\title{
Travel Agency Awareness of the Health Risks of International Travel; A Pilot Study
}

\author{
Gerard Flaherty ${ }^{1,2}$, Daniel Lim¹, Graham Fry ${ }^{3}$ \\ 1. School of Medicine, National University of Ireland, Galway, Ireland \\ 2. International Medical University, Kuala Lumpur, Malaysia \\ 3. Tropical Medical Bureau, Dublin, Ireland
}

*Corresponding Author: Gerard Flaherty, School of Medicine, National University of Ireland, Galway, Ireland Email: gerard.flaherty@nuigalway.ie

\begin{abstract}
Introduction: Travel agencies may be consulted by intending travelers seeking pre-travel health advice. Travel agents should be equipped to deal with such queries and have access to a source of high quality travel health advice. This study aimed to establish the level of knowledge of travel health risks among Irish travel agencies.

Methods: A web-based survey was distributed to travel agents affiliated with the Irish Travel Agents Association. The questionnaire recorded the travel agents' approach to clients seeking pre-travel health advice. Specific knowledge relating to health risks in specific destinations, the mode of spread of infectious tropical diseases and the need to direct clients to a source of professional travel health advice was assessed.

Results: Twenty four travel agents responded to the questionnaire. Sixty-three percent of respondents reported that traveling clients frequently seek their advice about destination health risks. The majority of travel agents respond to their enquiries by suggesting that the traveler attend their general practitioner or travel medicine specialist. Less than a third (32\%) of those questioned provide health information leaflets to their clients. The majority of agents estimated that fewer than $20 \%$ of travelers attend their practice with insufficient time remaining to consult with a healthcare professional. Travel agents generally underestimated the health risks associated with popular travel itineraries. There was a low level of knowledge of the mode of transmission of various tropical infectious diseases. The majority of respondents (81\%) welcomed an opportunity to engage with travel medicine specialists.
\end{abstract}

Conclusions: This study highlights the need to educate travel agents on travel health risks and travel health advice provision.

Keywords: Travel Agency, Awareness, Health Risks, International Travel, Travel Industry

Article History: Received: 25 Feb 2015; Revised: 2 May 2015; Accepted: 18 May 2015

Cite this article as: Flaherty G, Lim D, Fry G. Travel agency awareness of the health risks of international travel; a pilot study. Int J Travel Med Glob Health. 2015; 3(2):458

\section{Introduction}

Travel agents occupy a central role in the travel industry and may be consulted by intending travelers seeking pre-travel health advice. Van Herck and coworkers surveyed departing passengers traveling to developing countries at various European airports and found that $20 \%$ of respondents had consulted a travel agency for pre-travel health advice [1]. The knowledge of travel agents may be broad but may lack depth [2]. It is important that front-line travel agency staff are equipped to deal with such queries and have access to sources of reliable travel health information from qualified sources [3]. This is especially important when so-called last minute travelers book their trips with a travel agent very shortly before departure, when insufficient time remains to attend a travel medicine specialist.

Travel agencies represent an important potential source of basic information about malaria, recommended travel vaccinations, and other health risks. Little is known about the capacity of travel agency personnel to provide essential health information to travelers. Previous studies highlighted deficiencies in the health-related advice provided by travel agencies in the United Kingdom [4], and in Switzerland [5]. A study of notified cases of gastroenteritis in returned travelers revealed that only $36 \%$ of patients could recall having received health advice from a travel agent [6]. The travel industry concerns about the impact of discussing health risks on their business may account for at least some of their reluctance to address healthrelated issues during consultations with travelers [7].

The present study was the first of its kind to examine the situation pertaining to the travel agency sector in the Republic of Ireland. The aim of this study was to establish the level of knowledge of travel health risks among a sample of Irish travel agents in an effort to identify travel health educational needs in this community. Specific objectives included the following: to describe the approach of travel agents to clients seeking pre-travel health advice, and their confidence in providing such advice; to assess the level of knowledge of travel agents with regard to the geographical distribution of major tropical diseases and their mode of spread; to explore the awareness of sources of specialized travel health advice among the travel agent community in Ireland; and to identify training needs of travel agents in relation to travel health. 


\section{Methods}

The ethics committee approval was not required for this study. A 16-item questionnaire was developed and refined following a piloting process. Permission was obtained from the Irish Travel Agents Association (ITAA) to distribute the web-based questionnaire, created on Survey Monkey ${ }^{\circledR}$, anonymously to its members via an emailed web link. ITAA represents some 100 companies in 140 branches throughout the Republic of Ireland. Data were analyzed using descriptive statistical functions in Microsoft Excel.

The questionnaire sought information regarding the travel agents' usual practices in relation to requests for travel health information received from clients. Respondents were asked to estimate the proportion of travelers who had insufficient time remaining before departure to consult a healthcare professional. They were asked if they provided health information leaflets to clients, whether a series of popular holiday destinations presented a risk of contracting malaria, how a series of named tropical infectious diseases were transmitted, and they were asked to rate their level of confidence in providing basic travel health advice on a range of possible exposures, including sun injury, animal bites, insect bites, and food and water safety.

Travel agents were presented with 11 common holiday itineraries and asked to consider whether the travelers concerned should be referred to a specialist travel medicine clinic in each case. They were also asked how frequently they advise travelers to purchase travel medical insurance. The survey also enquired about the travel agents' training, if any, in travel health, and which educational activities they would favor from a list of 6 options provided.

\section{Results}

\subsection{Approach to Travel Health-Related Queries}

Responses were received from 24 travel agents. Sixty-three percent of travel agents reported that travelers seek their advice about the health risks faced in their chosen destination frequently, very frequently or always. The majority of travel agents (74\%) identified travel medicine specialists as their preferred source of pre-travel health advice, followed by General Practitioners (GPs, 57\%) and GP practice nurses (39\%). Most travelers (90\%) attend their travel agency with sufficient time remaining to consult with a healthcare professional before they depart. The majority of travel agents (81\%) welcomed an opportunity to speak to a travel medicine specialist in response to an enquiry from a client. Over two thirds of travel agents (67\%) believed that a closer professional relationship with a travel medicine clinic would help them provide an enhanced service to their own clients.

\subsection{Travel Agent Knowledge of Travel Health Issues}

The travel agents surveyed demonstrated satisfactory levels of awareness of the global distribution of malaria, but they incorrectly identified a malaria risk in the following popular tourist destinations: Cape Town (42\%), Rio de Janeiro (50\%), Inca trail (83\%), Japan (33\%) and Fiji (24\%). There was a poor level of knowledge of the mode of transmission of the following infectious diseases in travelers: hepatitis A, polio, Japanese B encephalitis, yellow fever and schistosomiasis. A significant proportion of the travel agents surveyed would not recommend that travelers on the following itineraries obtain pre-travel health advice: a 1-year trip to Australia on a working visa with visits to New Zealand and Fiji (50\%); a 2-week Mediterranean cruise (100\%); a Trans-Siberian railway crossing (40\%); a 2-week trip to Beijing (42\%), and a 1week package holiday in Tunisia (91\%).

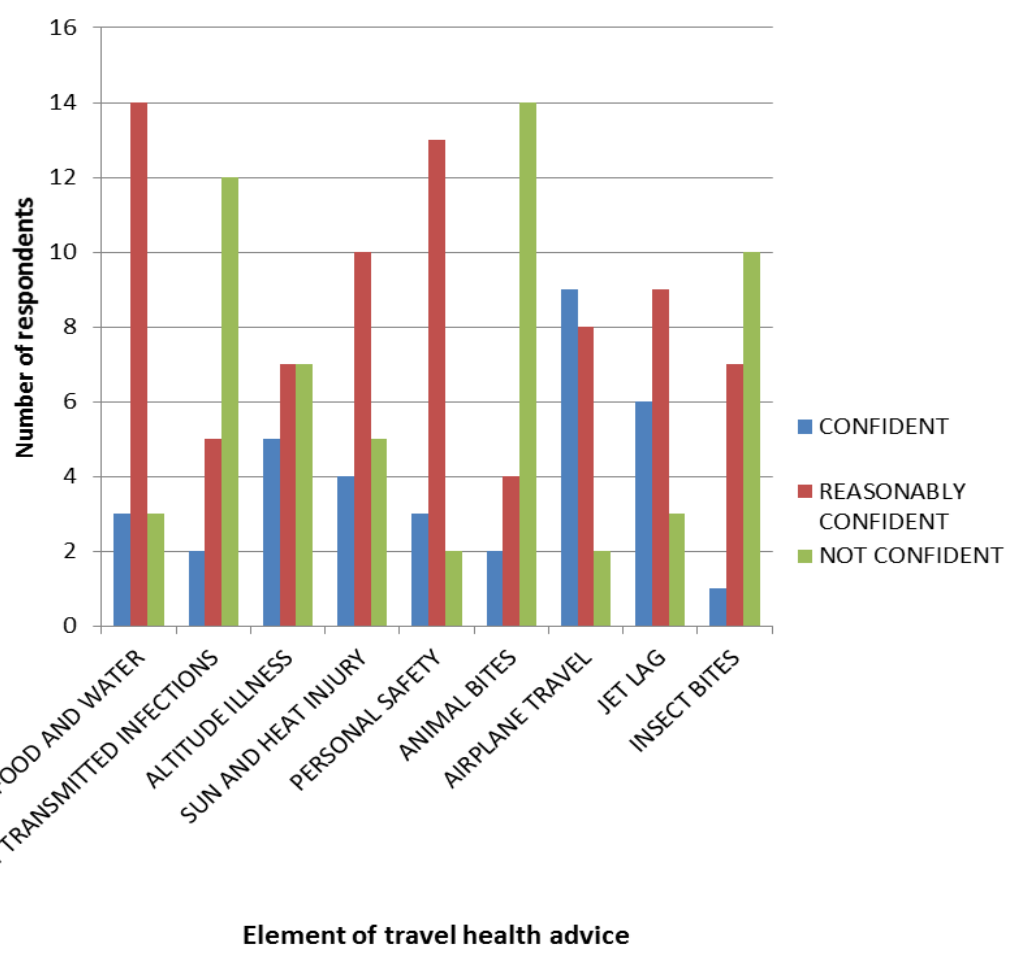

Figure 1. Travel agent confidence in the provision of travel health advice 
Travel agents expressed generally low levels of confidence in providing basic pre-travel health advice to travelers relating to a range of travel health risks (Figure 1), with the highest levels of confidence recorded for air travel advice and jet lag, and the lowest levels of confidence expressed for provision of information about animal bites, sexually transmitted infections, insect bites, and altitude.

The vast majority of travel agents surveyed expressed a desire to receive or update their existing knowledge in travel health through various educational channels (Figure 2), with particular preference given to a user friendly website and an information booklet. A minority of travel agents (32\%) provided travel health information leaflets to their existing clients.

\section{Discussion}

This study, though limited by its small sample size, provides valuable insights into the current practices of travel agency professionals operating in the Republic of Ireland. The finding that nearly two thirds of travel agents are regularly faced with travel health queries from their client travelers underscores the importance of this group as a source of preventive advice, especially where the traveler has chosen to forgo or bypass advice from a healthcare professional. This is especially critical in the case of the last minute traveler, although these were only encountered about $20 \%$ of the time in the sample of travel agents surveyed.

Leggat highlights the value of providing timely travel health advice to travelers, often by means of travel brochures and contact with travel agents [8]. In a larger study conducted in 202 travel agencies throughout the UK [4], the researchers found that no spontaneous health advice was offered in $61 \%$ of consultations involving destinations which were endemic for malaria. After receiving a prompt from the covert researchers, $71 \%$ of the agents surveyed provided general health advice, $67 \%$ suggested that the client seek professional malaria advice from a GP, and $37 \%$ of agents specified that malaria chemoprophylaxis was indicated for the particular itinerary involved. The authors concluded that travel agents provided health advice in an inconsistent fashion, mentioning travel health risks only when prompted by the traveler. In a study of 88 Swiss travel agencies [5], unprompted health advice was offered in $44 \%$ of all consultations. This improved to $99 \%$ of all travel agents following prompting by the covert researcher, but only $69 \%$ of travel agents suggested the need for travel vaccinations. In a study of 163 registered travel agencies in Cuzco, Peru, it was found that the majority of travel agencies failed to provide adequate information regarding the risks and prevention of malaria and yellow fever to travelers contemplating trips to the southern Amazonian region of Peru [9]. Cossar et al. advocate caution with regard to the advice given by travel agents to travelers, as incorrect information may provide a false sense of security or encourage risk-taking behavior [10]. The potential negative impact of conflicting health advice on traveler compliance with malaria chemoprophylaxis has been discussed previously in a cohort study of travelers consulting various sources of travel health advice [11].

Travel agency underestimation of risk was apparent from the findings of this study, with several popular itineraries being evaluated as low risk. This may have stemmed from a misperception about the likely environmental exposures involved, or from a tendency to attribute low risk to short duration vacations where railway or cruise ship travel is employed, for example. There was a striking lack of confidence among travel agents in their ability to provide basic preventive advice to the traveling public, particularly in relation to sexually transmitted infections, high altitude, insect bites, and animal bites. This is worrying given the potentially devastating consequences of contracting HIV infection, high altitude pulmonary or cerebral edema, malaria, and rabies, all of which can be avoided by promoting careful behavioral responses in the traveling population. There may be an embarrassment factor at play in the case of sexually transmitted infections, and the travel agent may feel constrained by the restrictions imposed by their commercial relationship with the client and the personal nature of some of the advice required.

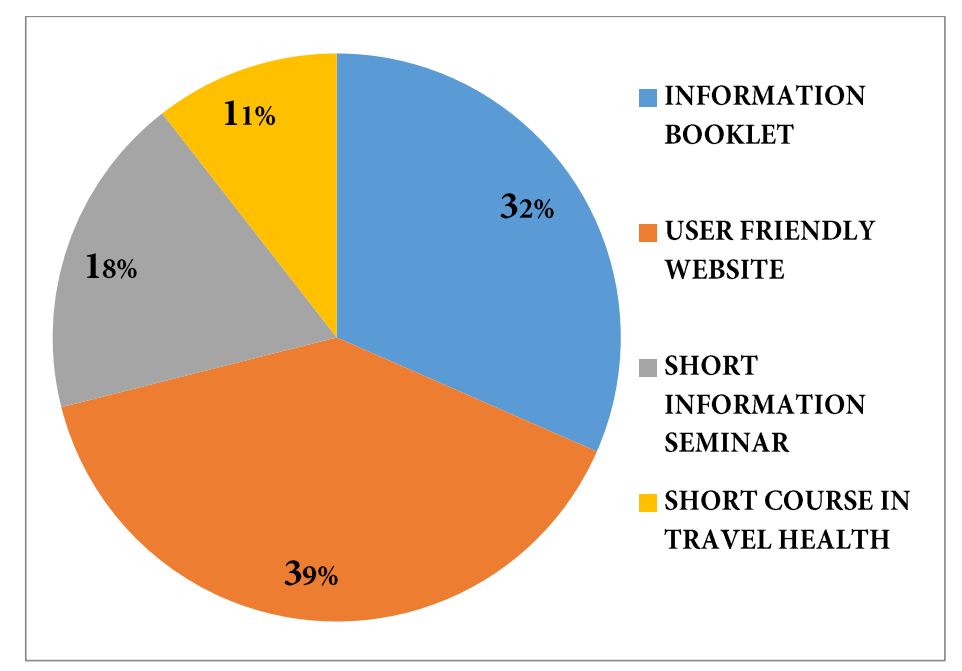

Figure 2. Preferred sources of travel health advice among travel agents 
The majority of travel agents in this study welcomed a greater level of cooperation between their industry and specialist travel medicine practitioners. There is scope for distributing standardized health information leaflets to all travelers who book their holidays through travel agencies, especially given the fact that so few travel agents provide health information leaflets of their own. In a study of the quality of health advice in high street travel brochures, Shickle et al. concluded that $64 \%$ of brochures consigned health information to the end of the brochure, often in a small font, and $25 \%$ were devoid of any health information [12]. Reid and colleagues previously stated that there should be greater collaboration between doctors, health educators and the travel industry [13].

We found that travel agents had a preference for onward referral of clients to their GPs, a finding supported by a previous study of travel agents in New Zealand [14]. Information on appropriate referral criteria of clients to healthcare practitioners may be provided to travel agents by means of workshops, brochures, email list-serves, or via the Internet. Such a referral pathway would minimize concerns about medicolegal liability on the part of the travel agency [15]. Schwitz and colleagues stressed the need to make accurate information about travel health risks freely available to travel agencies and to develop structured training for travel agencies in conjunction with healthcare providers [5]. There is a similar need to make reliable information accessible for travelers who arrange their travel plans entirely online without the intervention of a travel agency, and the current practices in this regard are deserving of detailed study.

\section{Conclusion}

This study highlights the need to educate travel agents on travel-related health risks and travel health advice provision in order to safeguard the welfare of their traveling clients. Until greater cooperation exists between travel agencies and local travel medicine clinics, travel agents should routinely refer their clients to the patient's GP if their travel plans permit. The study was limited by its small sample size and should be extended to include a larger sample of travel agents using data obtained by a covert researcher recording the actual health information provided, with and without interviewer prompting.

\section{Acknowledgements}

The authors wish to acknowledge the assistance of the Chief Executive of the Irish Travel Agents Association, Mr. Simon Nugent, in distributing our questionnaire to its members.

\section{Authors' Contribution}

The authors were involved in the study design, data collection, interpretation of the results, and preparation of the manuscript.

\section{Funding/Support}

None received.

\section{Financial Disclosure}

The authors state that they have no financial interests to disclose.

\section{References}

1. Van Herck K, Zuckerman J, Castelli F, Van Damme P, Walker E, Steffen R, European Travel Health Advisory Board. Travelers' knowledge, attitudes, and practices on prevention of infectious diseases: results from a pilot study. J Travel Med 2003;10:75-78.

2. McKercher B, Packer T, Yau MK, Lam P. Travel agents as facilitators or inhibitors of travel: perceptions of people with disabilities. Tourism Manag. 2003;24:465-74.

3. Seelan ST, Leggat PA. Health advice given by general practitioners for travelers from Australia. Travel Med Infect Dis. 2003;1:47-52.

4. Grabowski P, Behrens RH. Provision of health information by British travel agents. Trop Med Int Health. 1996;5:730-32.

5. Schwitz FM, Haley TJL, Stat C, Hatz CFR. Health information given by Swiss travel agencies. J Travel Med. 2006;13:294-99.

6. Packham CJ. A survey of notified travel-associated infections: implications for travel health advice. J Public Health 1995;17(2):217-22.

7. Bauer IL. Health advice in Australian travel brochures. J Travel Med 2002;9:263-66

8. Leggat PA. Sources of health advice given to travelers. J Travel Med 2000;7:85-88.

9. Villanueva-Meyer PG, Garcia-Jasso CA, Springer CA, Lane JK, Su BS, Hidalgo IS, et al. Advice on malaria and yellow fever prevention provided at travel agencies in Cuzco, Peru. J Travel Med 2015;22(1):26-30.

10. Cossar JH, McEachran J, Reid D. Holiday companies improve their health advice. BMJ. 1993;306:1070-71.

11. Phillips-Howard PA, Blaze M, Hurn M, Bradley DJ. Malaria prophylaxis: survey of the response of British travellers to prophylactic advice. BMJ. 1986;293:932-4.

12. Shickle D, Nolan-Farrell MZ, Evans MR. Travel brochures need to carry better health advice. Commun Dis Public Health. 1998;1(1):413.

13. Reid D, Cossar JH, Ako TI, Dewar RD. Do travel brochures give adequate advice on avoiding illness? BMJ. 1986;293:1472.

14. Lawton G, Page S. Evaluating travel agents' provision of health advice to travellers. Tourism Management. 1997;18(2):89-104.

15. MacDougall L, Gyorkos T. Promoting travel clinic referrals: exploring partnerships for healthier travel. Social Science and Medicine. 2001;53:1461-68. 